\title{
EFFECTIVENESS OF AN EXERCISE TRAINING PROGRAM ON YOUTH WITH ASPERGER SYNDROME
}

\author{
Erwin Borremans, Pauli Rintala*, Marko Kielinen **
}

\author{
Keskuspuisto Vocational Institute, Helsinki, Finland \\ ${ }^{*}$ University of Jyväskylä, Jyväskylä, Finland \\ ** University of Oulu, Oulu, Finland
}

\begin{abstract}
Although exercise training programs are effective in improving physical fitness and motor competence in typically developing youth, insufficient data of the impact of interventions are available in youth with Asperger syndrome (AS). The purpose of this study was to examine the efficacy of an exercise program as part of an ongoing vocational training program for adolescents with AS on motor competence and physical fitness. Twenty adolescents with AS (mean age = 16.8yrs) were enrolled in this study. A quasi-experimental nonequivalent-control-group design with a follow-up measurement over a period of six months was followed. The intervention group received a 12-week physical exercise program focusing on improving motor competence and physical fitness. The structured activity program was applied 3 days a week for 1 hour. Data collection included pre-, post-, and follow-up evaluations using the Movement Assessment Battery for Children (M-ABC-II) and the EUROFIT physical fitness test together with training diaries and comments from teachers and guardians. Two $2 \mathrm{X} 3$ repeated measures ANOVAs indicated improved motor competence and physical fitness that was sustained over time. The exercise training program was successful with adolescents with AS and implementation of similar programs is therefore recommended.
\end{abstract}

KEYWORDS: Asperger syndrome, exercise, training program, physical activity, motor skills, physical fitness, M-ABC-II, EUROFIT, youth.

\section{INTRODUCTION}

The promotion of physical exercise and activity through physical education is very important for all, but especially for individuals with special needs, like youth with Asperger syndrome (AS). Since the earliest descriptions of AS, individuals with this neurological disorder have been observed to exhibit, besides difficulties in social interaction and communication, poor motor skills and clumsiness (Frith, 1991). Estimates of the prevalence of these motor problems range up to 85\% (Attwood, 1998, 2007; Borremans, Rintala, \& McCubbin, 2009; Gillberg \& Gillberg, 1989; Klin, Volkmar, Sparrow, Cicchetti, \& Rourke, 1995; Manjiviona \& Prior, 1995; Sahlander, Mattsson, \& Bejerot, 2008; Smith, 2000).
According to previous research (Borremans, Rintala, \& McCubbin, 2008; Borremans et al., 2009) this lower motor competence is reflected by difficulties in throwing or catching balls, keeping balance, or mastering more complex movements like hopping or skipping. Common features also include stiff awkward gait patterns, difficulties to run as fast as their peers, and being unable to perform some everyday tasks that require fine motor skills like tying shoe laces. Most of the participating adolescents with AS in the Borremans et al. studies were at risk for physical inactivity and scored significantly lower than an age and gender matched comparison group on the second edition of the Movement Assessment Battery for Children (M-ABC-II) and on the EUROFIT physical fitness test (Borremans et al., 2008, 2009). Differences were found in all components of 
both test batteries, including fine motor skills, balance, ball skills, coordination, flexibility, muscular strength, running speed and cardiorespiratory endurance. In line with our observations this combination of motor and fitness challenges is likely a major reason why regular physical education is often disliked by youth with Asperger syndrome.

There has been an increase in number of descriptive investigations on AS in the areas of identification, assessment, characteristics and associated symptoms. However, intervention studies have been scarce, especially those to improve motor skills, physical fitness, and ability to function in everyday life. Several intervention studies with individuals with motor impairment, such as developmental coordination disorder (DCD), have shown positive learning results (Peters \& Wright, 1999; Schoemaker, Hijlkema, \& Kalverboer, 1994; Sugden \& Chambers, 2003; Watemberg, Waiserberg, Zuk, \& Lerman-Sagie, 2007). In these studies various methods, such as process and task oriented approaches, specific group exercise programs or other approaches used by physiotherapist, were proven effective. Research by Peters and Wright (1999) reported improved motor competence using the M-ABC in a group of fourteen children with DCD after participating in a 10-week (for 1 hour a week) specific group exercise program designed by a physiotherapist. Also Sudgen and Chambers (2003) found significant improvement in motor skills after conducting a 40-week (3 times around 20 minutes) exercise program with 31 children with DCD using parents and teachers as co-therapists. Watemberg et al. (2007) reported improvements in motor competence after their intervention with children who had a combination of attention-deficit-hyperactivity disorder (ADHD) and DCD. The provided intensive physical therapy intervention had a marked impact on the motor performance of these children.

It is not surprising that such an expert input from skilled professionals would work. However, it is clear that with a relatively high prevalence of $0.4 \%$ (Mattila et al., 2007), exploring means of support other than through specialized service providers has become a priority and we are convinced that adequate physical exercise can play an important role to fill this need. The widespread problem of physical inactivity, along with lower levels of motor competence and physical fitness, underscores the need to promote healthy lifestyles in adolescents with AS through regular exercise. Within our vocational training setting there was a need to create more exercise opportunities, as physical well-being is also key to academic success (Sallis et al., 1999). To date, the effectiveness of an exercise training program has not yet been evaluated on individuals with AS. Therefore, the purpose of this study was to examine the effects of a structured exercise training program on motor competence and physical fitness of adolescents with AS.

\section{METHOD}

\section{Participants and study design}

Twenty adolescents diagnosed with Asperger syndrome volunteered as participants. The group was recruited from different vocational training units in Southern Finland and consisted of sixteen males and 4 females with average age of 16 years and 9 months (SD 10months). This gender distribution is in line with the most recent epidemiological data where males outnumber females (Ehlers, Gillberg, \& Wing, 1999; Mattila et al., 2007). All participants met the diagnostic criteria for AS as presented in the ICD-10 (World Health Organisation, 1993) and were diagnosed prior to enrollment by a professional with considerable experience diagnosing people with AS. Intellectual disability and psychosis were used as exclusion criteria. Prior to all investigations, written assent was obtained from the participants and written consent from their legal guardians. The institutional ethical committee approved the study design and participant recruitment.

This study made use of a quasiexperimental nonequivalent-control-group design with a follow-up measurement, which is a widespread experimental design in educational research and particularly 
appropriate to research in schools (Thomas, Nelson, \& Silverman, 2005). Three observations were made each 3 months apart (Pre-test - Intervention - Post-test - Follow-up) over a total period of 6 months. The follow-up observation was added to the pre-post -test design to see whether possible effect of treatment was maintained over time. The participants were divided into two groups matched for age, gender, and initial M-ABC-II scores. Groups were randomly assigned to either the intervention or control group. The investigator was not blinded to the intervention offered.

\section{Intervention}

The intervention group received an intensive 12-week exercise training program, whereas the other group of 10 served as the control group and did not receive the intensive program. This exercise training program, called "Move your body \& Stretch your mind", consisted of a variety of motor activities easily available to the student and her/his family, and explained in simple text with pictures. When planning the program some additional considerations were made such as: student preferences, lifetime sports and activities, regional and seasonal sports and games, alternative sports and activities that are easily accessible in the community (e.g. swimming, running, skating). Conducting activities that provide for maximum involvement, as well as develop the necessary physical, social, and cognitive skills needed for physical fitness, were prioritized. This approach encouraged students to take a personal responsibility for fitness and develop an exercise training program for use both in and out of school.

The participants were supposed to exercise 3 times per week, for an hour per session. The program consisted of three main parts: an extra-curricular physical exercise program in the community, an exercise program with stations focusing on core and stretching, and an aerobic physical activity of choice. First, once a week a voluntary extra-curricular training was organized right after school in a sports center nearby and was lead by the principal investigator. The activities promoted positive attitudes towards physical activity and encouraged the participants to be active in leisure time by providing activities and games that can be easily transferred towards leisure time (e.g., floor ball, soccer, badminton). Second, students were supposed to do at home a core exercise program with stations including warm-up, core work out and stretching. These core exercises help strengthen core muscles and also improve balance and overall coordination. All students got personal training and instruction about the exercises prior to the home program and received a printout of the exercises with pictures. Third, students were asked to be engaged for an hour in an aerobic physical activity of their choice, such as biking, swimming, running, Nordic walking, aerobics, within their own community setting. The first part of the intervention was led by the student's physical education teacher (in this case principal investigator), whereas the second and third parts were done at home with their guardians as co-teachers.

A written exercise contract, about what, where, when and with whom to do the home program, was made between each student and the researcher. This type of contract has been identified as an effective reinforcer in our program for students with AS to increase participation and improve exercise adherence. All participants were also asked to carefully complete their exercise diary. The participants regularly asked questions about their training and received weekly reminders about their training diaries from the principal investigator. During the project there were also regular contact with teachers and guardians. Informal contact was made and the teachers and guardians were briefed about the specific schedule of the intervention and received a copy of the exercise contract to inform of what was going to happen. This way they could provide support and assistance to fulfill the exercise requirements when needed. Teachers and guardians were encouraged to contact the primary investigator if there were any challenges or if they had recommendations to more appropriate activities for their participants. 


\section{Instruments}

\section{Movement ABC-II}

Motor competence was assessed with the updated version of the Movement Assessment Battery for Children, the M-ABC-II (Henderson, Sugden, \& Barnett, 2007). This M-ABC-II test has proven reliable and valid (Chow \& Henderson, 2003; Faber \& Nijhuis van der Sanden, 2004; Henderson et al., 2007) and previous versions of it have been commonly used in motor competence research with individuals with AS (Green et al., 2002; Manjiviona \& Prior, 1995; Miyahara et al., 1997; Siaperas, Holland, \& Ring, 2006). The M-ABC-II test contains eight tasks that assess three components of functioning: manual dexterity, balance, and ball skills. The manual dexterity tasks include turning pegs both with preferred and non-preferred hand, a bimanual task to make a triangle with nuts and bolts, and a drawing trail. The tests for ball skills include aiming and throwing at a wall target, as well as catching a ball with one hand. Balance items consist of two-board balancing, toe-to-heel backwards walking, and zigzag hopping. The three domains were assessed in all participants. The raw scores obtained for each item were first converted to standard scores and summed to obtain a total test score using age related norms. This total test score was used for dataanalysis. The test provides also percentiles for each age group through 16 . According to the M-ABC-II manual scores at or below the $5^{\text {th }}$ percentile (total test score $\leq 56$ ) are considered indicative of significant motor difficulty and scores between the $6^{\text {th }}$ and $15^{\text {th }}$ percentile suggest being at risk for having motor problems.

\section{EUROFIT}

Physical fitness was assessed using selected items of the EUROFIT, the European test of physical fitness. The EUROFIT test items were chosen because they are widely employed within European schools and used annually in adapted physical education assessments in the participating schools. For this reason students had a certain familiarity level with the test items. Considering the difficulty individuals with AS may have with change and new routine, this familiarity is an important reason for choosing the EUROFIT. A detailed description of the test items is given in Oja \& Tuxworth (1995) and in Borremans et al. (2008). The battery of fitness tests used in this study contained 8 tasks and included the assessment of the following components: flexibility (sit-and-reach), musculoskeletal fitness (sit-up, handgrip strength, standing broad jump), motor fitness (tests for balance (single leg balance) and speed of movement (plate tapping and $5 \times 10$ shuttle run)) and aerobic fitness $(2 \mathrm{~km}$ walking test). The items of this test battery are reliable and valid and this instrument is commonly used to measure physical fitness in children and adults in Europe (e.g., Mac Donncha, Watson, McSweeney, \& O’Donovan, 1999). Because the EUROFIT manual does not provide a total fitness score, a T-score based on the sum of all subtests T-scores' divided by the amount of tests, was calculated to achieve a more total physical fitness score.

\section{Informal descriptive questionnaire}

A short questionnaire was developed to gather some simple anecdotal comments about the student's feelings towards the intervention program. Questions about their likes and dislikes concerning the exercise program were answered with open responses. The aim was to better understand and support the current findings and improve the program for the future use. The information obtained from this questionnaire is not included in the main analysis, but findings are taken into consideration in the discussion.

\section{Procedures}

A team of three experienced clinicians (two physiotherapists and one occupational therapist) assessed the participants 3 times, each 12 weeks apart, in 2008. In a quiet classroom, the assessment was initiated with a short interview and an informative briefing about the test situation supported with pictures of the test items. The manual dexterity, balance, ball and physical fitness tests were then administered. In total, this session took approximately 1.5 hours. 


\section{Data analysis}

Two 2 X 3 (group by time) repeated measures (RM) ANOVA was used to examine differences in motor competence and physical fitness between intervention- and control group at different times. Post-hoc comparisons to determine significant differences of main effects were examined through one-way (time) repeated measures ANOVA for each group. Six one-way RM ANOVAs (three for each measure) were used to test the pairwise comparisons for the intervention and control groups with Bonferroni correction $(\mathrm{p} \leq .017$ [.05/3 [i.e., pre vs. post, post vs. follow-up, and pre vs. follow-up]). All statistical analyses were computed using the statistical software PASW version 17 (SPSS, 2009).

\section{RESULTS}

Table 1 presents the means and SDs for motor competence and physical fitness scores of each group across the three time periods. The most relevant statistics for our purposes are the three means reflecting these performance scores. Examination of these means suggests that the average motor competence as well as physical fitness for the intervention group was lowest at pre-test (before the intervention), highest at post-test (immediately after the intervention), and in between these two at follow-up (the 3-month follow-up measure).

\section{Table 1}

Means and SDs for motor competence and physical fitness scores of each group across the three time periods

\begin{tabular}{lcccc}
\hline & \multicolumn{2}{c}{ Motor competence } & \multicolumn{2}{c}{ Physical fitness } \\
& \multicolumn{2}{c}{ total test score } & \multicolumn{2}{c}{ total score } \\
\hline & Intervention & Control & Intervention & Control \\
& group & group & group & group \\
Time & $\mathrm{M} \pm \mathrm{SD}$ & $\mathrm{M} \pm \mathrm{SD}$ & $\mathrm{M} \pm \mathrm{SD}$ & $\mathrm{M} \pm \mathrm{SD}$ \\
Pre test & $53.8 \pm 21.6$ & $56.6 \pm 12.0$ & $50.3 \pm 7.9$ & $49.8 \pm 5.1$ \\
Post test & $62.6 \pm 19.2$ & $58.9 \pm 11.7$ & $53.4 \pm 5.0$ & $49.9 \pm 5.2$ \\
Follow-up & $61.6 \pm 19.3$ & $56.8 \pm 12.7$ & $52.7 \pm 5.5$ & $49.3 \pm 5.0$ \\
\hline
\end{tabular}

A graphic picture of the group results of the M-ABC-II total test score is shown in Figure 1. This figure shows a great improvement in performance between pre- and post-test for the intervention group and a slight improvement in the control group followed by a leveling off to the follow-up test for both groups. 


\section{Figure 1}

Mean total test scores of the M-ABC-II for both intervention and control group with AS ( $\mathrm{n}=$ 10/group)

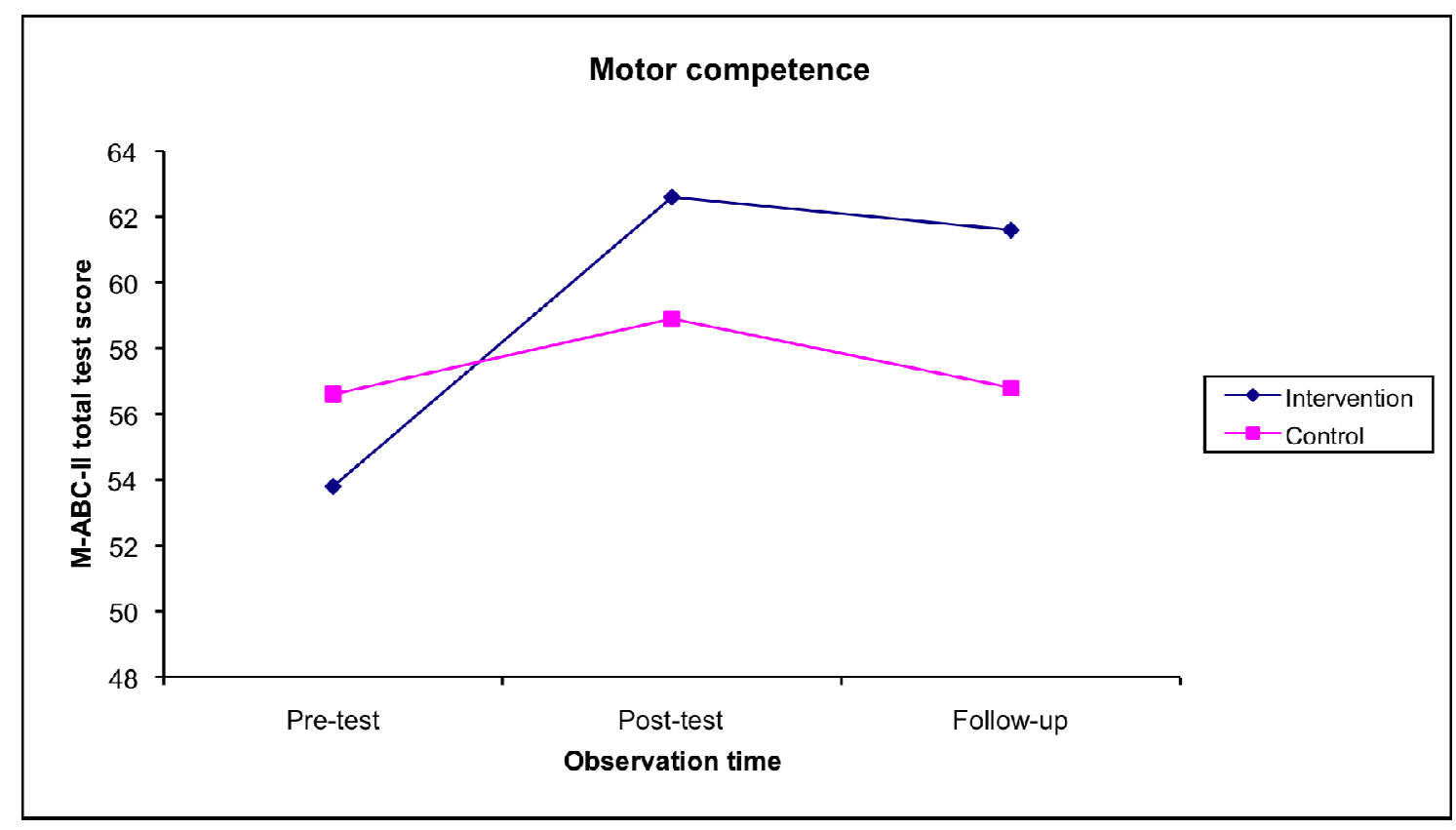

For the M-ABC-II the $2 \mathrm{X} 3$ repeated measures ANOVA revealed a significant interaction between group and time: $\mathrm{F}(2,36)=$ 6.96; $\mathrm{p}<0.005$; partial eta squared $=.28$ representing a large effect. Post-hoc comparisons through one-way (time) repeated measures ANOVA for each group revealed the following. For the intervention group there was a simple main effect for time, $F(2,18)=$ $10.58, \mathrm{p}<0.001$, partial eta squared $=.54$. The Bonferroni method indicated a significant mean difference between pre- and post-test (exact $p=$ .002 ), pre-test and follow-up (exact $\mathrm{p}=.005$ ), but not for post-test and follow-up (exact $\mathrm{p}=$ .64). Also for the control group a simple main effect was found for time: $F(2,18)=7.04 ; p<$ 0.01 ; partial eta squared $=.44$. Here the
Bonferroni method indicated only a significant mean difference between pre- and post-test (exact $\mathrm{p}=.002$ ), but not between post-test and follow-up (exact $\mathrm{p}=.019$ ), nor for pre-test and follow-up (exact $p=.79$ ), indicating that the possible gains are not maintained.

Similar results were observed by analyzing the graphic picture and data of the EUROFIT. A graphic picture of the group results of the EUROFIT total test score is shown in Figure 2. This figure shows a large improvement in performance between pre- and post-test for the intervention group and only a slight improvement in the control group followed by a leveling off to the follow-up test for both groups. 


\section{Figure 2}

Mean total test T-scores of the EUROFIT physical fitness test for both intervention and control group with AS ( $n=10$ /group).

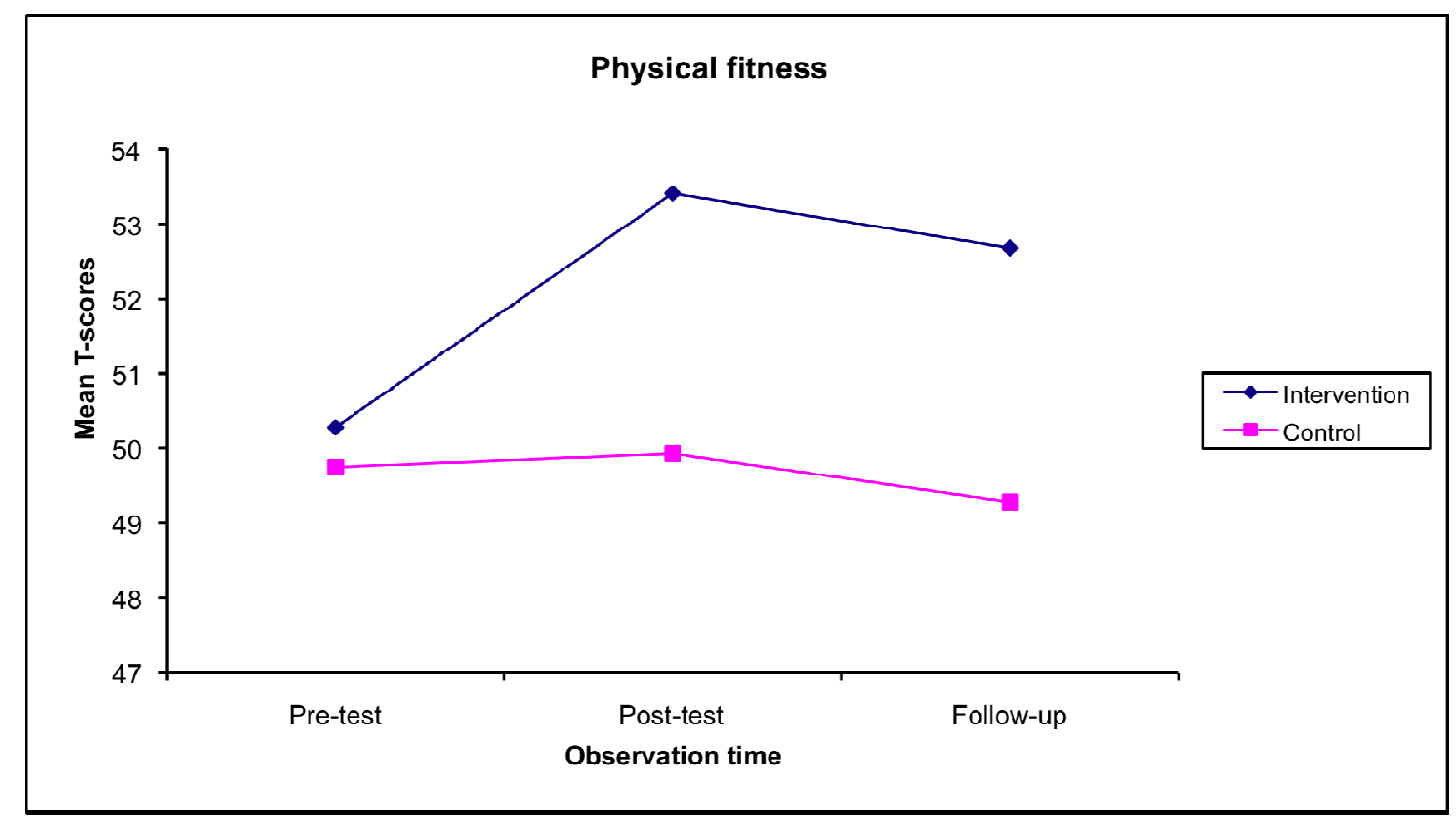

Also for the EUROFIT the 2 X 3 repeated measures ANOVA revealed a significant interaction between group and time: $\mathrm{F}(2,36)$ $=4.48 ; \mathrm{p}<0.05 ;$ partial eta squared $=.20$ representing a large effect. Post-hoc comparisons through one-way (time) repeated measures ANOVA for each group revealed the following. For the intervention group there was a simple main effect for time, $F$ $(2,18)=4.39, \mathrm{p}<0.05$, partial eta squared $=$ .33. The Bonferroni method indicated no significant mean differences between different test times with exact $p=.11$ between pre- and post-test, exact $\mathrm{p}=.96$ between posttest and follow-up, and exact $\mathrm{p}=.26$ for pretest and follow-up. Also for the control group a simple main effect for time, $F(2,18)=5.69$, $\mathrm{p}<0.05$, partial eta squared $=.38$ was found. The Bonferroni method indicated no significant mean differences between times. The exact p-values between pre- and post-test, post-test and follow-up, and pre-test and follow-up were respectively $\mathrm{p}=.99, \mathrm{p}=.05$, and $\mathrm{p}=.13$.

Based on these results, it seems that there is an interaction effect only between pre- and post-tests for both measures, in that the treatment group increased their levels significantly more than the control group. However, the levels of both groups slightly decreased at the follow-up without any meaningful differences between post-test and follow-up.

To address the effects of history, matched groups were established based upon pre-test M-ABC-II score. A confirmatory independent $t$-test, showed no significant differences at pre-test between the intervention and the control group with $\mathrm{t}(18)=2.45 ; \mathrm{p}>.05$. The average pre-treatment $\mathrm{M}$-ABC-II percentile score was 15 (SD 20) for the intervention group and 12 (SD 14) for the control group, both scores within the range of at risk for motor problems. In both groups there was large within group variability with 4 participants in the intervention and 3 in the control group scoring above the $15^{\text {th }}$ percentile. All but one participant in the intervention group improved their M-ABC-II score between pre- and post-test, with the average $\mathrm{M}$-ABC-II score increasing from percentile 15 to percentile 25 . In the control group little improvement was observed and the average M-ABC-II score stayed below the $15^{\text {th }}$ percentile. 


\section{DISCUSSION}

A significant proportion of adolescents with AS have delayed motor development and are in need of effective programs to improve motor competence and physical fitness (Borremans et al., 2008, 2009). The present study used an exercise training program that proved efficacious in improving the motor competence and physical fitness of adolescents with AS. Where the $p$ value for the difference in motor competence between pre and post-test for the intervention was significant, such a significance was not observed for physical fitness, yet we claim that also this difference is meaningful as a similar upwards trend is observed as in motor competence (see Figures $1 \& 2$ ). Lack of statistical significance may be due to the small sample size and the high SD. Therefore, these results need to be interpreted in relation to both, statistical significance and clinical importance.

The individuals in the control group returned to pre-test levels of motor competence and physical fitness at the follow-up, whereas a much slighter decline was observed for the intervention group. The intervention group ended the 6 months period with higher levels of motor competence and physical fitness. When individuals with AS invest some extra time weekly to be physically active, skill and fitness levels increase. These results follow a similar positive upwards trend of increasing competence levels as other exercise interventions in children with poor motor skills (e.g., Peters \& Wright, 1999; Schoemaker et al., 1994; Watemberg et al., 2007).

Even though the intervention was effective for the majority of participants, more research is needed to further evaluate which aspects of the exercise intervention were most successful and which aspects need to be adapted or improved. Although a multi-level approach, like the one used in the present study, makes it difficult to identify which aspects of the interventions were successful, we discovered that such an approach is more appropriate to target adolescents' physical activity behavior, which is influenced by a diversity of factors. By offering different exercise possibilities such as an extra physical education class or a personal home program students get a wider scope of possible ways to increase their healthy exercise behavior.

\section{Some recommendations for clinical practice}

Because many adolescents with AS have lower motor competence, physical fitness, and activity levels than recommended for good health, increased opportunities for extracurricular interventions need to be encouraged (Borremans et al., 2008, 2009). Based upon our experience an increase in active physical exercise time can be achieved by including key strategies such as: providing choice of developmentally appropriate physical activities, the use of cooperative games and activities that include all students, engagement in activities that cater to the needs and interests of all students, and making exercise enjoyable and fun. Also the students who were interviewed about their experiences with the home program proposed themselves similar strategies. In their view "fun physical exercise" rules!

When asked about which parts of the exercise program they liked the most, the common answer was the extra exercise class held after school (with a very high attendance rate). The second most popular was the voluntary aerobic exercise and the least popular was the personal exercise program. On average the students in the intervention group were able, according to their own records, to exercise around $2 / 3$ of the recommended exercise time. The students' preference for the group exercise training was little surprising, as in earlier research it was concluded that students with AS in general rather tend to opt for activities in solitude (Borremans et al., 2008). When exercise training programs are tailor-made, enjoying the exercise can be achieved more easily. At the same time other important skills, like social and group skills, could be worked on. While planning exercise program we recommend that educators not only teach movement skills, but they should also teach key socially appropriate behavioral skills, 
such as goal setting, self-monitoring, and enlisting support for physical activity.

The extra-curricular exercise program of this study has proven to be effective in promoting skill and fitness and such a program could contribute to achieve recommended PA levels when integrated into the broader individualized education program. Given the variability in developmental profiles of individuals with AS, it should be expected that not all benefit equally from the interventions. There is not a one-for-all treatment thus the interventions must be prescribed in an individualized manner consistent with the functional goals for each student. Given that many conventional educational environments are loud, distracting and unpredictable, interventions need to consider the individualized adaptations to optimize successful participation and adherence in the exercise programs. The program and instruction should therefore emphasize enjoyable participation in the training program and help students develop the knowledge, attitudes, motor and behavioral skills needed to adopt and maintain physically active lifestyles.

Limitations of the study and recommendations for future research

Although statistically our small sample size represents a study limitation, it is noteworthy to state that meaningful differences in motor competence and physical fitness levels were found that provide support for the exercise training program effectiveness. The quasi-experimental design, with sample of convenience, also limits generalizability. Although we did not assess the relationship between other important characteristics of AS such as social interaction, communication, and also sensory processing, ongoing research is crucial to better understand the impact of these abilities in an exercise environment. The logical next step in this line of research is to use a more targeted intervention program that includes both exercise training and theory-based, physical activity motivational strategies to increase not only fitness levels and motor competence, but also long-term leisure-time physical activity. Also dose response to exercise and the effect of exercise on academic success are areas that need further investigation.

\section{Conclusion}

Design limitations notwithstanding, it can be concluded that the exercise training program was effective in promoting motor competence and physical fitness in adolescents with AS. Because many of these adolescents are at risk for physical inactivity and do not meet the recommended physical activity levels for good health, the implementation of extracurricular interventions needs to be encouraged.

\section{ACKNOWLEDGEMENTS}

This research was funded in part by a grant from the Finnish Ministry of Education (OPM, Valtionavustus 2009). The authors would like to thank Sanna Blair and Hariet Valovirta for their expert assistance with data collection and Jeff McCubbin for his editorial comments. We are also very grateful to the staff, parents and participants for their time and assistance, which they generously contributed to this study.

\section{REFERENCES}

Attwood, T. (1998). Asperger's syndrome : a guide for parents and professionals. London: Jessica Kingsley Publishers.

Attwood, T. (2007). The complete guide to Asperger syndrome. London: Jessica Kingsley Publishers.

Borremans, E., Rintala, P., \& McCubbin, J. A. (2008). Physical fitness and physical activity in adolescents with Asperger syndrome: A comparative study. Manuscript submitted for publication.

Borremans, E., Rintala, P., \& McCubbin, J. A. (2009). Motor skills of young adults with Asperger syndrome: A comparative study. European Journal of Adapted Physical Activity, 2(1), 21-33. Retrieved september 3, 2009, from http://www.eufapa.upol.cz/www /images/stories/files/Journals/vol1_2/ 02Borremans.pdf 
Chow, S. M., \& Henderson, S. E. (2003). Interrater and test-retest reliability of the Movement Assessment Battery for Chinese preschool children. American Journal of Occupational Therapy, 57, 574-577.

Ehlers, S., Gillberg, C., \& Wing, L. (1999). A screening questionnaire for Asperger syndrome and other high-functioning autism spectrum disorders in school age children. Journal of Autism and Developmental Disorders, 29, 129-141.

Faber, I. R., \& Nijhuis van der Sanden, M. W. G. (2004). The Movement Assessment Battery for Children. Standardisation and reliability of Age Band 5: young adults. In S.E. Henderson, D. Sugden \& A. Barnett (Eds.), The Movement Assessment Battery for Children-2. (2007 ed.). London: Pearson Assessment.

Frith, U. (1991). Autism and Asperger syndrome. Cambridge: Cambridge University Press.

Gillberg, I. C., \& Gillberg, C. (1989). Asperger syndrome - some epidemiological considerations: a research note. Journal of Child Psychology and Psychiatry and Allied Disciplines, 30, 631-638.

Green, D., Baird, G., Barnett, A. L., Henderson, L., Huber, J., \& Henderson, S. E. (2002). The severity and nature of motor impairment in Asperger's syndrome: a comparison with specific developmental disorder of motor function. Journal of Child Psychology and Psychiatry and Allied Disciplines, 43, 655-668.

Henderson, S., Sugden, D., \& Barnett, A. L. (2007). Movement Assessment Battery for Children-2. London: Pearson Assessment.

Klin, A., Volkmar, F. R., Sparrow, S. S., Cicchetti, D. V., \& Rourke, B. P. (1995). Validity and neuropsychological characterization of Asperger syndrome: convergence with nonverbal learning disabilities syndrome. Journal of Child Psychology and Psychiatry and Allied Disciplines, 36, 1127-1140.

Mac Donncha, C., Watson, A. W. S., McSweeney, T., \& O'Donovan, D. J. (1999). Reliability of Eurofit physical fitness items for adolescent males with and without mental retardation. Adapted Physical Activity Quarterly, 16, 86-95.

Manjiviona, J., \& Prior, M. (1995). Comparison of Asperger syndrome and high-functioning autistic children on a test of motor impairment. Journal of Autism and Developmental Disorders, 25, 23-39.

Mattila, M. L., Kielinen, M., Jussila, K., Linna, S. L., Bloigu, R., Ebeling, H., et al. (2007). An epidemiological and diagnostic study of Asperger syndrome according to four sets of diagnostic criteria. Journal of the American Academy of Child and Adolescent Psychiatry, 46, 636-646.

Miyahara, M., Tsujii, M., Hori, M., Nakanishi, K., Kageyama, H., \& Sugiyama, T. (1997). Brief report: motor incoordination in children with Asperger syndrome and learning disabilities. Journal of Autism and Developmental Disorders, 27, 595-603.

Oja, P., \& Tuxworth, B. E. (1995). Eurofit for adults: A test battery for the assessment of the health-related fitness of adults: Council of Europe, Committee for the Development of Sport.

Peters, J. M., \& Wright, A. M. (1999). Development and evaluation of a group physical activity programme for children with developmental co-ordination disorder: An interdisciplinary approach. Physiotherapy Theory \& Practice, 15, 203216.

Sahlander, C., Mattsson, M., \& Bejerot, S. (2008). Motor function in adults with Asperger's disorder: a comparative study. Physiotherapy Theory and Practice, 24, 7381.

Sallis, J. F., McKenzie, T. L., Kolody, B., Lewis, M., Marshall, S., \& Rosengard, P. (1999). Effects of health-related physical education on academic achievement: project SPARK. Research Quarterly for Exercise and Sport, 70, 127-134.

Schoemaker, M. M., Hijlkema, M. G., \& Kalverboer, A. F. (1994). Physiotherapy for clumsy children: an evaluation study. Developmental Medicine and Child Neurology, 36, 143-155. 
Siaperas, P., Holland, T., \& Ring, H. (2006). Discriminative validity of the Movement ABC Test and Checklist for use with children with Asperger syndrome. In S. E. Henderson, D. Sugden \& A. Barnett (Eds.), Movement Assessment Battery for Children2 (2007 ed.). London: Pearson Assessment.

Smith, I. M. (2000). Motor functioning in Asperger syndrome. In A. e. a. E. Klin (Ed.), Asperger syndrome (pp. 97-124). New York: The Guilford Press. .

SPSS (2009). PASW Statistics 17 for

Windows. Chicago, IL.: SPSS Inc.

Sugden, D. A., \& Chambers, M. E. (2003). Intervention in children with Developmental Coordination Disorder: the role of parents and teachers. The British Journal of Educational Psychology, 73, 545-561.

Thomas, J. R., Nelson, J. K., \& Silverman, J. (2005). Research methods in physical activity (5th ed.). Champaign: IL: Human Kinetics.

Watemberg, N., Waiserberg, N., Zuk, L., \& Lerman-Sagie, T. (2007). Developmental coordination disorder in children with attention-deficit-hyperactivity disorder and physical therapy intervention.

Developmental Medicine and Child Neurology, 49, 920-925.

World Health Organisation (1993). International statistical classification of diseases and health-related problems, Tenth Revision (ICD-10). Geneva: Author.

Corresponding author's e-mail address: erwin.borremans@gmail.com

\section{MOTORISCHE FERTIGKEITEN JUNGER ERWACHSENER MIT ASPERGER SYNDROM: EINE VERGLEICHSSTUDIE}

(Resümee)

Obwohl Trainingsprogramme zur Verbesserung von körperlicher Fitness und motorischer Kompetenz sich als effektiv bei typisch entwickelten Jugendlichen erwiesen haben, liegt nur ungenügendes Datenmaterial über den Einfluss von solchen Interventionen bei Jugendlichen mit Asperger Syndrom (AS) vor. Die Absicht dieser Studie war es, die Effektivität eines Übungsprogramms für motorische Kompetenz und körperliche Fitness zu prüfen, das als Teil eines Berufsausbildungsprogramms für Jugendliche mit AS angeboten wurde. Zwanzig Jugendliche mit AS (Durchschnittsalter $=16.75$ Jahre) waren an dieser Studie beteiligt. Ein quasi-experimentelles, nicht gleichwertiges Kontrollgruppen-Design mit einer Nachfolge-Messung nach einer Periode von sechs Monaten schloss daran an. Die Interventionsgruppe wurde einem 12-wöchigen Übungsprogramm unterzogen, das darauf abzielte, motorische Kompetenz und körperliche Fitness $\mathrm{zu}$ verbessern. Das strukturierte Bewegungsprogramm wurde an drei Tagen der Woche über eine Stunde durchgeführt. Die Datengewinnung umfasste in ihren Vor-, Nach- und Folge-Evaluierungen die Movement Assessment Battery for Children (M-ABC-II) und den EUROFIT-Physical-FitnessTest zusammen mit Trainingstagebüchern und Kommentaren von Lehrenden und Betreuenden. Zwei 2x3 wiederholte ANOVA-Messungen ergaben verbesserte motorische Kompetenz und nachhaltige Verbesserung der körperlichen Fitness. Da dieses Trainingsprogramm erfolgreich für Jugendliche mit AS zu sein schien, wird die Implementierung ähnlicher Programme daher empfohlen.

SCHLÜSSELWÖRTER: Asperger Syndrom, Übungs-/Trainingsprogramm, Bewegung, Motorische Fertigkeiten, Körperliche Fitness, M-ABC-II, EUROFIT, Jugendliche. 


\section{LES HABILETES MOTRICES DE JEUNES ADULTES ATTEINTS DU SYNDROME D'ASPERGER : UNE ETUDE COMPARATIVE \\ (Résumé)}

Bien que les programmes d'entraînement soient efficaces pour améliorer la condition physique et les compétences motrices chez des jeunes en développement, il n'existe pas assez de données sur l'impact de ces interventions chez des jeunes atteints du syndrome d'Asperger (AS). L'objectif de cette étude était d'examiner l'efficacité d'un programme d'activité physique inclut dans un programme de formation professionnelle sur la compétence motrice et la condition physique d'adolescents atteints d'AS. Vingt adolescents atteints d'AS (âge moyen $=16,75$ ans) ont été inclus dans cette étude. Un plan quasi-expérimental avec groupe contrôle non équivalent et un suivi sur 6 mois a été mené. Le groupe intervention a bénéficié d'un programme d'activité physique de 12 semaines orienté sur l'amélioration des compétences motrices et la condition physique. Le programme structuré d'activité physique se déroulait 3 fois par semaine pour une durée d'une heure. La collecte de données incluait des évaluations pré, post et de suivi en utilisant le M-ABC-II (Movement Assessment Battery for Children) et le test de condition physique EUROFIT associé à un journal d'activité physique ainsi que des commentaires des parents et des tuteurs. Deux ANOVA à mesures répétées $2 \mathrm{X}$ ont fait ressortir une amélioration des compétences motrices et de la condition physique qui était maintenue dans le temps. Le programme d'activité physique a eu du succès auprès d'adolescents atteints d'AS. La mise en œuvre de programmes similaires est recommandée.

MOTS CLEFS: Syndrome d'Asperger, exercice, programme d'activité physique, activité physique, habiletés motrices, condition physique, M-ABC-II, EUROFIT, adolescents. 